\title{
Characteristics of Indoor and Outdoor Fine Phthalates during Different Seasons and Haze Periods in Beijing
}

\author{
Yu Wang, Ding Ding, Mushui Shu, Zhiyong Wei, Tong Wang, Qi Zhang, Xiaohui Ji, \\ Pengyao Zhou, Mo Dan*
}

Beijing Municipal Institute of Labour Protection, Beijing 100054, China

\begin{abstract}
We studied the concentrations, seasonal distributions, sources, exposures, and health risks of phthalates in indoor and outdoor $\mathrm{PM}_{2.5}$ in Beijing. The results showed that phthalate concentrations during haze periods were significantly higher than during non-haze periods both indoors and outdoors, with higher concentrations for the former, which reached a maximum of $1995.56 \mathrm{ng} \mathrm{m}^{-3}$. Phthalates are mainly derived from the use of indoor plasticized products, the outdoor plastic products industry, and other sources of fuel emissions. Lifelong exposure to fine (2-ethylhexyl) phthalate (DEHP) through inhalation and dermal absorption was calculated, and the results indicated a risk of cancer, with DEHP carcinogenic risk levels of $4.09 \times 10^{-6}$ and $10.50 \times 10^{-6}$ for adults and children, respectively. The highest DEHP carcinogenic risk group was 1-2-year-old children, and the risk decreased afterward with age.
\end{abstract}

Keywords: $\mathrm{PM}_{2.5}$; Indoor air; Exposure.

\section{INTRODUCTION}

Phthalic acid esters (PAEs, also called phthalates) are an important class of organic compounds and are widely used as plasticizers to improve the flexibility and workability of polymeric materials such as those in toys, food packaging, building materials, medical devices, electronics, vinyl flooring and wallpaper. Lower molecular weight PAEs are also used as solvents and/or fragrance in cleaning agents, lubricants, personal care products (e.g., nail polish, hair spray, soap, and shampoo), repellents, and hundreds of other products (Guo and Kannan, 2013; Škrbic et al., 2016). Growing concern about phthalates is related to their toxicity, in particular to their endocrine disrupting activity. Toxicological researches in both animal and human investigated that the most sensitive health outcomes following exposure to some PAEs were the adverse reproductive development effects, which included shortened anogenital distance observed in newborn boys, shortened pregnancy, destroyed testicles, lower sex and thyroid hormones, and reduced sperm quality observed in adults (Hauser et al., 2006; Axelsson et al., 2015; Al-Saleh et al., 2017). Exposure to some PAEs has been associated with the allergic symptom, asthma and neurodevelopmental problems in children (U.S. EPA, 2012;

\footnotetext{
* Corresponding author.

Tel.: 86-10-83522722

E-mail address: danmo2001@126.com
}

Bamai et al., 2016). Besides, the International Agency for Research on Cancer (IARC) (IARC, 1982) has listed DEHP as a possible carcinogen to humans (Group 2B; 1982). Due to the adverse health effects, many countries and organizations list some PAEs as priority control pollutants. For instant, the U.S. Environmental Protection Agency (U.S. EPA) has listed dimethyl phthalate (DMP), diethyl phthalate (DEP), dibutyl phthalate (DBP), butyl benzyl phthalate (BBP), phthalic acid (2-ethylhexyl) phthalate (DEHP), and dioctyl phthalate (DnOP) among 129 priority pollutants. DMP, DBP, DnOP are on the Chinese environmental priority pollutants blacklist, and DBP, DnOP, DEHP and BBP are also on the list of priority pollutant of the European Community (EC, 1997).

Because they are not chemically bound to polymeric matrices and thus easily released into the environment, PAEs have become the world's most widely distributed class of persistent environmental pollutants. Some studies have reported PAEs as a ubiquitous, even dominant class of organic compounds in outdoor airborne particulates worldwide-for example, in cities in India ( $\mathrm{Fu}$ et al., 2010), France (Teil et al., 2006), the Netherlands (Peijnenburg and Struijs, 2006), and China (Wang et al., 2006; Wang et al., 2008; Kong et al., 2013; Wang et al., 2018)—as well as in indoor gases, aerosols and home dusts (Wensing et al., 2005; Teil et al., 2006; Weschler et al., 2008; Pei et al., 2013; Zhang et al., 2014; Wang et al., 2014; Song et al., 2015).

As the capital of China, Beijing has experienced frequent severe haze pollution in recent years. Although extensive studies have investigated the chemical composition, sources, 
formation mechanisms, and health effect of haze episodes in Beijing (Sun et al., 2013, 2015, 2016), few studies have been conducted on atmospheric PAEs and none is involved in PAEs during haze period to our knowledge. People usually spend $80-90 \%$ of their time each day indoors (Castro et al., 2011), and indoor $\mathrm{PM}_{2.5}$ concentration is strongly affected by outdoor pollution (Zhao et al., 2015). Therefore, studying indoor and outdoor PAE pollution in Beijing is critical. This study investigated the distribution, pollution level, and main likely sources of PAEs in indoor and outdoor airborne fine particulates (fine PAEs) during haze and non-haze period to provide a basis for improving indoor air quality.

\section{EXPERIMENTAL METHODS}

\section{Sampling}

Paired outdoor and indoor $\mathrm{PM}_{2.5}$ samples were collected simultaneously at the Beijing Municipal Institute of Labor Protection building during the winter of 2015 and spring of 2016 (Fig. 1). This was a typical residential site with urban traffic, adjacent to busy roads to the south and west. The outdoor sampling point was the rooftop of the building, and the indoor sampling point was a room (third floor) in which no staff work. The room was $20 \mathrm{~m}^{2}$ and the sampling height $1.2 \mathrm{~m}$, simulating breathing zone height for favorable comparison of indoor and outdoor pollution. Sampling was conducted over 1 day (a period of $23 \mathrm{~h}$ ) or 2 days (a period of $48 \mathrm{~h}$ ) when the air quality was excellent using the URG3000 ABC particle sampler (with $\mathrm{PM}_{2.5}$ sampling head, 8.35 $\mathrm{L} \mathrm{min}^{-1}$ ) outdoors and the BUCK VSS-5 personal sampling pump (with $\mathrm{PM}_{2.5}$ sampling head, $4 \mathrm{~L} \mathrm{~min}^{-1}$ ) indoors. Both blank and sample filters were packed in aluminum foil and stored at $-18^{\circ} \mathrm{C}$ in the dark prior to gas chromatography-mass spectrometry (GC-MS) analysis.

\section{Extraction and GC-MS Analysis}

Aliquots of approximately $2.1 \mathrm{~cm}^{2}$ each were punched from sample filters and spiked with a known amount of perdeuterated tetracosane $\left(\mathrm{n}-\mathrm{C}_{24} \mathrm{D}_{50}\right)$ and perdeuterated benzoic acid $\left(\mathrm{C}_{7} \mathrm{HO}_{2} \mathrm{D}_{5}\right)$ as recovery standards prior to extraction (The amount of aliquots used was based on the organic carbon (OC) content, to ensure that the total OC mass in the aliquots was more than $1 \mathrm{mg}$ ). The aliquots were cut into pieces and extracted using three successive $10 \mathrm{~mL}$ solution of dichloromethane/methanol $(1: 1 ; \mathrm{v} / \mathrm{v})$ at three 15-minute intervals using ultrasonic extractors. The solvent extracts were combined and concentrated to approximately $5 \mathrm{~mL}$ using a rotary evaporator and blown to near-dryness with pure nitrogen gas; a $0.4-\mathrm{mL}$ dichloromethane/acetonitrile (3:1, v/v) solution was then added. The solutions were analyzed using GC-MS (6890 Plus GC, 5973N MSD; Agilent, Santa Clara, CA, USA) with a DB-5MS capillary column $(30 \mathrm{~m} \times 0.25 \mathrm{~mm} \times 0.25 \mu \mathrm{m}$; J\&W Scientific, Inc. $)$. The temperature program for GC consisted of a 10-min isothermal hold at $60^{\circ} \mathrm{C}$ followed by a ramp of $6^{\circ} \mathrm{C} \mathrm{min}^{-1}$ to $300^{\circ} \mathrm{C}$, and finally a 50 -min isothermal hold at $300^{\circ} \mathrm{C}$. MS was performed in electron ionization mode, with electron energy of $70 \mathrm{eV}$ and a mass scanning range of 50550 amu. Scanning modes included total ion current and selected ion monitoring. Data were gathered and processed using ChemStation software. GC-MS response factors were determined using authentic standards $\left(1000 \mu \mathrm{g} \mathrm{mL}{ }^{-1}\right.$, Lot 213081263, AccuStandard) for six PAEs, namely, DMP, DEP, DBP, BBP, DEHP, and DnOP. Recovery for most of the samples was in the range $60-120 \%$. Reagent blank, instrument blank, and sampling blank were analyzed along with the samples, and the concentrations of samples in this study were corrected according to the recovery rate and blank.

\section{RESULTS AND DISCUSSION}

\section{Concentration Levels and Seasonal Distribution of Fine $P A E s$ in Beijing}

The average concentration of indoor fine PAEs at the investigated location was $1288.03 \pm 379.02 \mathrm{ng} \mathrm{m}^{-3}$ and $856.59 \pm 217.93 \mathrm{ng} \mathrm{m}^{-3}$ during spring 2016 and winter 2015,

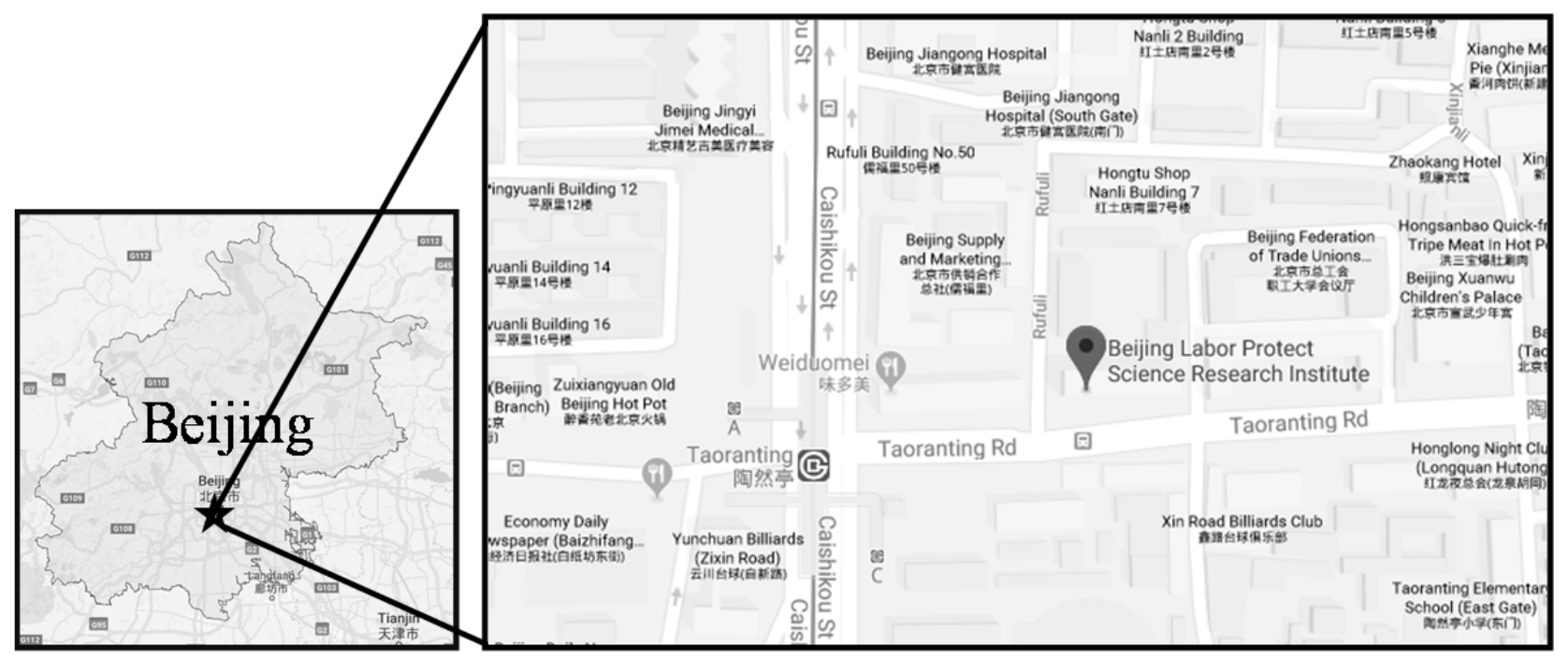

Fig. 1. Sample location map. 
respectively, whereas the outdoor fine PAE concentration was $455.82 \pm 97.65 \mathrm{ng} \mathrm{m}^{-3}$ in spring and $815.22 \pm 156.47 \mathrm{ng} \mathrm{m}^{-3}$ in winter. Compared with the concentrations of PAE aerosols in other studies, the concentrations of indoor PAEs in this study were considerably lower than those in indoor Hangzhou air (Pei, 2013), comparable to those in California (Rudel et al., 2003) and Berlin (Fromme et al., 2004), and much higher than those in Paris (Teil et al., 2006) (Table 1). Similarly, the concentrations of outdoor fine phthalates in this study were higher than those in Tianjin (Kong et al., 2013) and Taizhou (Gu et al., 2010). The comparison in Table 1 shows that the concentration of fine PAEs in Beijing was high. Few studies have been conducted on the PAEs present in indoor fine particles, and this is thus a new research avenue. Given the high PAE concentration and the stronger toxic effect of fine particles compared with large particles, more attention should be paid to fine PAEs in Beijing to increase knowledge about them and reduce the associated health risks.

Unlike other organic materials with fine particles, PAEs had an average concentration that was higher indoors than outdoors, especially during spring. This points to typical indoor emissions sources such as volatilization from plastics and paint. This means that phthalates in the indoor environment were primarily from indoor sources. This result was consistent with an analysis of phthalate contaminants in indoor air by Pei (2013), who stated that the indoor concentration was generally higher (being 124.7 times that of the outdoor concentration).

Different seasonal patterns were found regarding indoor and outdoor fine PAE concentrations during winter 2015 and spring 2016. For indoor fine PAEs, the average concentration in spring $\left(1288.03 \pm 379.02 \mathrm{ng} \mathrm{m}^{-3}\right)$ was higher than in winter $\left(856.59 \pm 217.93 \mathrm{ng} \mathrm{m}^{-3}\right)$. The outdoor fine PAE concentration showed the opposite seasonal pattern, being lower in spring $\left(455.82 \pm 97.65 \mathrm{ng} \mathrm{m}^{-3}\right)$ and higher in winter $\left(815.22 \pm 156.47 \mathrm{ng} \mathrm{m}^{-3}\right)$. These different seasonal distribution patterns were likely due to differing sources and dispersion conditions. With the temperature rising in spring, part of the more highly saturated vapor pressure components, such as DMP, evaporated, and the concentration in the particle phase thus decreased. Seasonal changes in the outdoor concentration were mainly due to industrial pollution sources, incineration of plastic waste, and the use of thin films for agricultural greenhouses, combined with adverse atmospheric dispersion conditions in winter, which cause phthalate concentrations to be maintained at a high level. Beijing was often windy in the spring, which was conducive to the spread and dilution of organic pollutants and was also why PAEs were difficult to collect from particles in the spring.

The effect of meteorological conditions was also assessed in Table 2 and Fig. 2. By studying the relationship between temperature and humidity in terms of concentrations of fine PAEs, we discovered that temperature and humidity had no significant correlation with fine PAEs concentration in winter or spring $(\mathrm{P}>0.05)$. Therefore, temperature and humidity had little effect on the concentrations of PAEs in $\mathrm{PM}_{2.5}$ in this study. Outdoor wind speed was low in winter and significantly decreased during periods of haze (Fig. 3). Convection slowed down, which was not conducive to the dispersion of PAEs. Therefore, outdoor PAE concentration was high in winter. In spring, however, the wind speed was higher and the atmospheric convection more intense, which could also explain why outdoor PAE concentration was higher in winter than in spring.

\section{Comparison of Indoor and Outdoor PAE Concentrations during Haze Periods}

The indoor and outdoor phthalate concentrations in

Table 1. Comparison of PAE concentrations in different regions $\left(\mathrm{ng} \mathrm{m}^{-3}\right)$.

\begin{tabular}{|c|c|c|c|c|c|c|}
\hline & Locations & Description & type & Size & Concentrations & References \\
\hline \multirow[t]{16}{*}{ Domestic } & Beijing, China & Spring, 2016 & outdoor & $\mathrm{PM}_{2.5}$ & 455.82 & This study \\
\hline & & Winter, 2015 & outdoor & $\mathrm{PM}_{2.5}$ & 815.22 & \\
\hline & & Spring, 2016 & indoor & $\mathrm{PM}_{2.5}$ & 1288.03 & \\
\hline & & Winter, 2015 & indoor & $\mathrm{PM}_{2.5}$ & 856.59 & \\
\hline & Beijing, China & - & indoor & TSP & 1138 & Shen, 2009 \\
\hline & Beijing, China & Winter, 2003 & outdoor & $\mathrm{PM}_{2.5}$ & 179 & Li et al., 2015 \\
\hline & & Summer, 2003 & outdoor & $\mathrm{PM}_{2.5}$ & 408 & \\
\hline & Chongqing, China & Winter, 2003 & outdoor & $\mathrm{PM}_{2.5}$ & 335 & Li et al., 2015 \\
\hline & & Summer, 2003 & outdoor & $\mathrm{PM}_{2.5}$ & 1162 & \\
\hline & Hangzhou, China & Autumn, 2011-Spring, 2012 & indoor & TSP & 4718 & Pei, 2013 \\
\hline & Tianjin, China & Jan., Apr., and Jul., 2010 & outdoor & $\mathrm{PM}_{10}$ & 113.78 & Kong et al., 2013 \\
\hline & & & outdoor & $\mathrm{PM}_{2.5}$ & 85.65 & \\
\hline & Xi'an, China & Sep., 2012-Jan., 2013 & indoor & TSP & $90-14770$ & Wang et al., 2014 \\
\hline & Xi'an, China & Dec., 2013 & outdoor & $\mathrm{PM}_{2.5}$ & $271.7-2134$ & Wang et al., 2017 \\
\hline & Taizhou, China & Jul., 2006 & outdoor & $\mathrm{PM}_{2.5}$ & 216.4 & Gu et al., 2010 \\
\hline & & Jan., 2007 & outdoor & $\mathrm{PM}_{2.5}$ & 326.6 & \\
\hline \multirow[t]{4}{*}{ Abroad } & California, America & Jun., 1999-Sep., 2001 & indoor & $\mathrm{PM}_{2.5}$ & 887 & Rudel et al., 2003 \\
\hline & Paris, France & May., 2002-Apr., 2003 & indoor & TSP & $3.9-13.0$ & Teil et al., 2006 \\
\hline & Berlin, Germany & $2000-2001$ & indoor & TSP & 918 & Fromme et al., 2004 \\
\hline & Gosan, Korea & Mar., and Apr., 2005 & outdoor & TSP & $8-47$ & Wang et al., 2009 \\
\hline
\end{tabular}


Table 2. Samples and weather information.

\begin{tabular}{|c|c|c|c|c|c|c|c|c|c|}
\hline \multirow{2}{*}{ Season } & \multirow{2}{*}{$\begin{array}{l}\text { Weather } \\
\text { conditions }\end{array}$} & \multirow{2}{*}{ Sampling date } & \multicolumn{2}{|c|}{ Temperature $\left({ }^{\circ} \mathrm{C}\right)$} & \multicolumn{2}{|c|}{ Humidity $(\%)$} & \multirow{2}{*}{$\begin{array}{l}\text { Pressure } \\
(\mathrm{hPa})\end{array}$} & \multirow{2}{*}{$\begin{array}{l}\text { Visibility } \\
(\mathrm{km})\end{array}$} & \multirow{2}{*}{$\begin{array}{l}\text { Wind speed } \\
\left(\mathrm{km} \mathrm{h}^{-1}\right)\end{array}$} \\
\hline & & & Outdoor & Indoor & Outdoor & Indoor & & & \\
\hline \multirow[t]{9}{*}{ Spring } & \multirow[t]{3}{*}{ Non-haze } & 2016.3 .5 & 7 & 30 & 21 & 13 & 1020 & 6 & 19 \\
\hline & & 2016.3 .7 & 4 & 29 & 28 & 13 & 1022 & 11 & 13 \\
\hline & & 2016.3 .9 & 1 & 30 & 19 & 9 & 1033 & 30 & 18 \\
\hline & \multirow[t]{4}{*}{ Haze } & 2016.3 .13 & 4 & 29 & 26 & 12 & 1024 & 14 & 13 \\
\hline & & 2016.3 .15 & 8 & 29 & 39 & 15 & 1017 & 5 & 8 \\
\hline & & 2016.3 .17 & 9 & 30 & 59 & 20 & 1012 & 3 & 6 \\
\hline & & 2016.3.18 & 12 & 29 & 41 & 17 & 1012 & 4 & 8 \\
\hline & \multirow[t]{2}{*}{ Non-haze } & 2016.3 .19 & 11 & 29 & 36 & 17 & 1022 & 8 & 10 \\
\hline & & 2016.3 .20 & 10 & 29 & 39 & 16 & 1026 & 9 & 6 \\
\hline \multirow[t]{8}{*}{ Winter } & \multirow[t]{3}{*}{ Non-haze } & 2015.11 .22 & -2 & 24 & 95 & 19 & 1036 & 4 & 5 \\
\hline & & 2015.11 .23 & -3 & 24 & 70 & 16 & 1038 & 11 & 8 \\
\hline & & 2015.11 .25 & -6 & 22 & 65 & 14 & 1032 & 11 & 14 \\
\hline & \multirow[t]{4}{*}{ Haze } & 2015.11 .27 & -6 & 23 & 72 & 11 & 1026 & 4 & 5 \\
\hline & & 2015.11 .28 & -2 & 22 & 76 & 14 & 1029 & 2 & 5 \\
\hline & & 2015.11 .29 & 1 & 23 & 80 & 16 & 1027 & 3 & 3 \\
\hline & & 2015.12 .1 & -1 & 23 & 96 & 20 & 1020 & 1 & 5 \\
\hline & Non-haze & 2015.12 .2 & 2 & 25 & 36 & 10 & 1021 & 13 & 21 \\
\hline
\end{tabular}
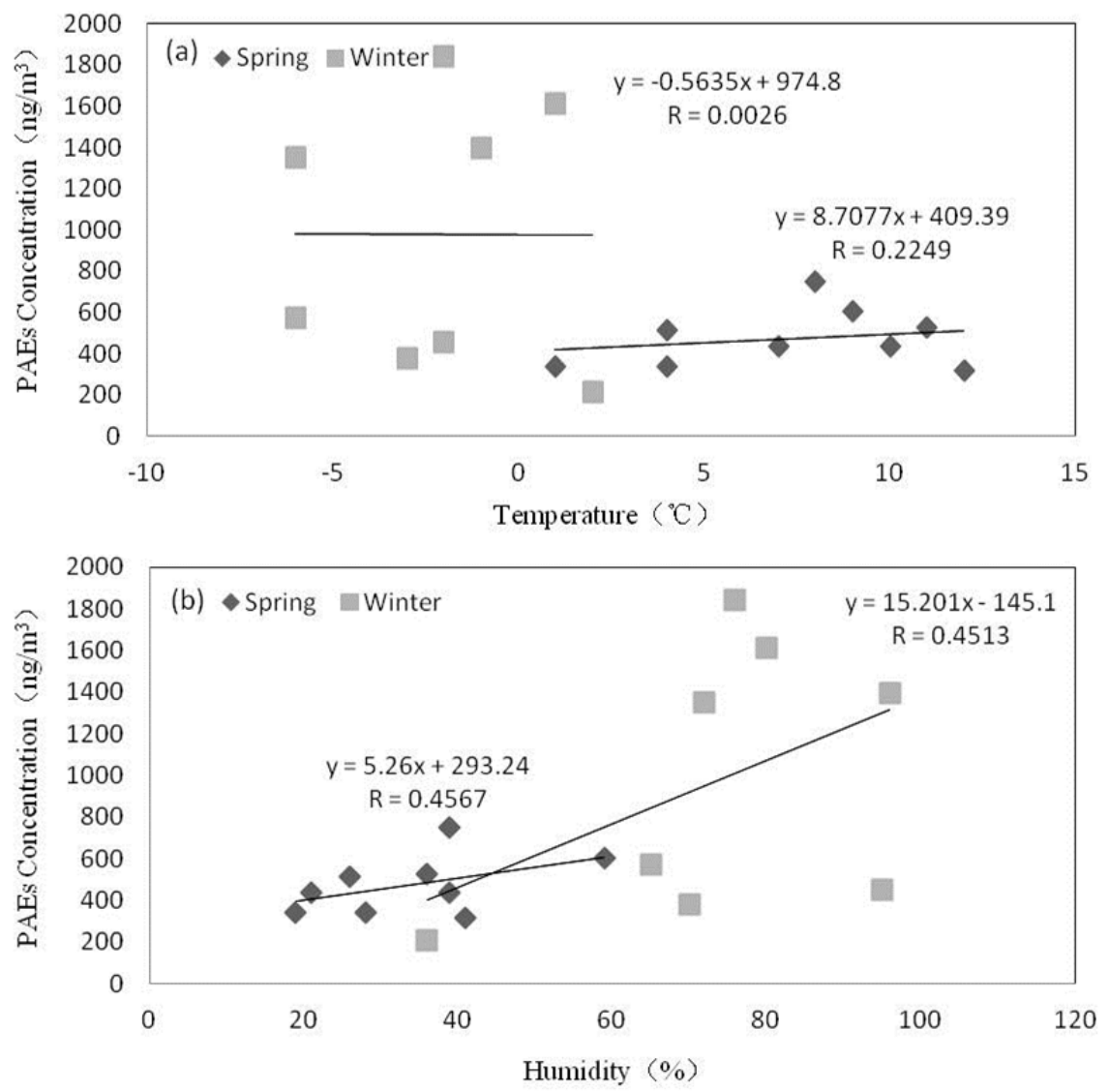

Fig. 2. The effect of temperature and humidity on mass of phthalate concentrations.

different polluted weather conditions on different dates are shown in Fig. 3. During the pre-haze period of winter, the indoor fine phthalates concentration was 915.02 \pm 231.40 $\mathrm{ng} \mathrm{m}^{-3}$, whereas it was $470.39 \pm 106.00 \mathrm{ng} \mathrm{m}^{-3}$ outdoors. During the period of haze, the indoor concentration was slightly higher at $940.15 \pm 223.46 \mathrm{ng} \mathrm{m}^{-3}$, whereas the outdoor concentration was considerably higher at 1549.03 $\pm 284.58 \mathrm{ng} \mathrm{m}^{-3}$. In the pre-haze period of spring, the indoor and outdoor fine phthalate concentrations were $1235.76 \pm$ $396.78 \mathrm{ng} \mathrm{m}^{-3}$ and $363.20 \pm 80.84 \mathrm{ng} \mathrm{m}^{-3}$, respectively, whereas during the haze period these values were 1389.68 $\pm 384.55 \mathrm{ng} \mathrm{m}^{-3}$ and $574.27 \pm 136.67 \mathrm{ng} \mathrm{m}^{-3}$. 

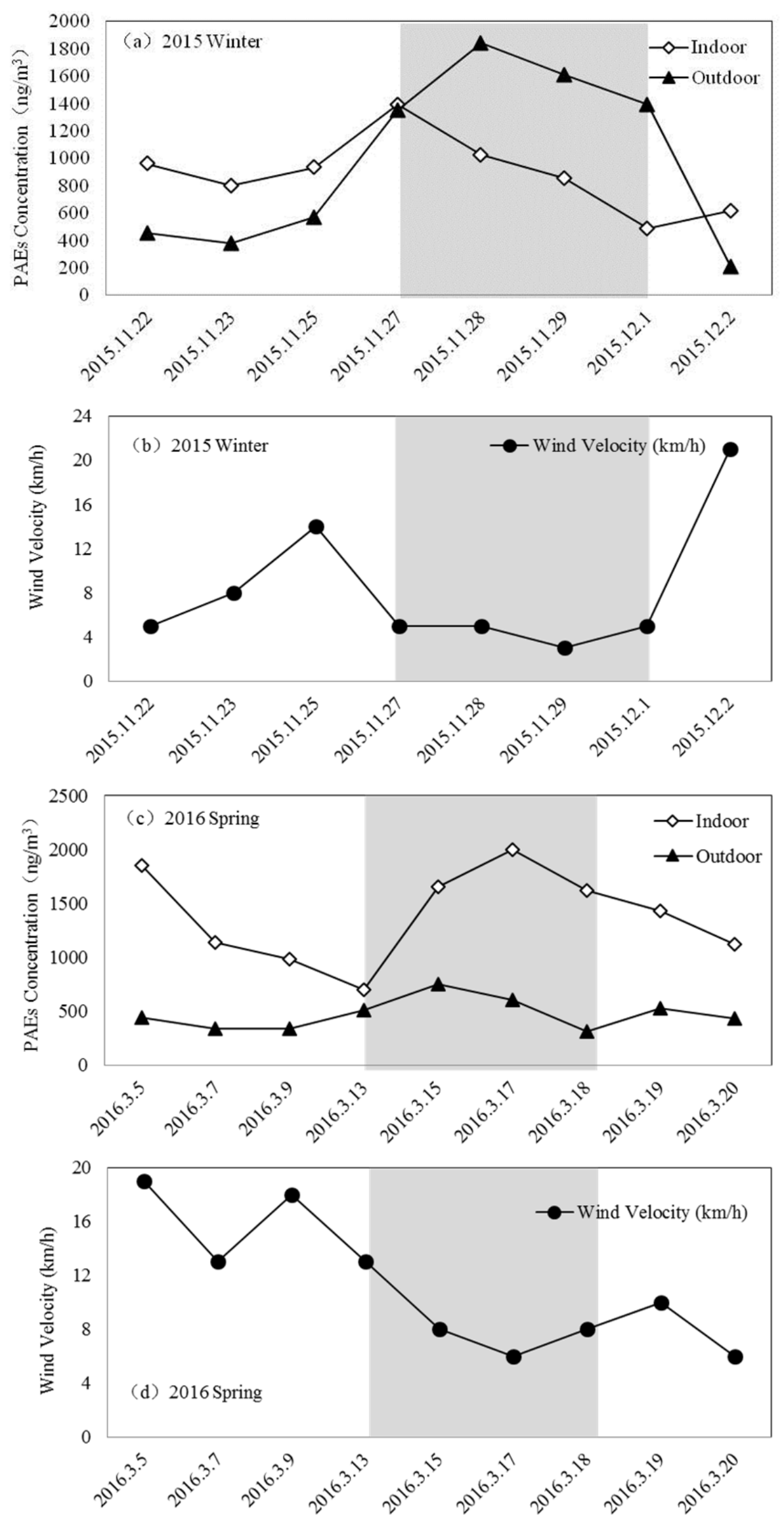

Fig. 3. Mass of phthalate concentrations in indoor and outdoor $\mathrm{PM}_{2.5}$ during haze and meteorological condition effects. 
During the entire haze period of spring, the indoor and outdoor PAE concentration trends were extremely similar (Fig. 3). In hazy conditions, indoor and outdoor fine PAE pollution showed a clear upward trend, with a maximum PAE concentration of $1995.56 \mathrm{ng} \mathrm{m}^{-3}$. Fig. 4 shows that DEHP was the PAE monomer with the most significantly increased concentration of indoors in the spring haze, as for outdoors the increase in PAE concentration was mainly due to DEHP, with a small increase in the DMP concentration.

Fine PAE concentrations in the period of winter haze showed a different trend. In the pre-haze period, PAE concentration was generally higher indoors than outdoors, with the concentrations having the same trend. When the haze period began, the outdoor PAE concentration gradually increased, whereas the indoor concentration showed no obvious change. At the end of the haze period, the indoor and outdoor PAE concentrations gradually returned to their pre-haze synchronization trend, with indoor concentration higher than that outdoors. During the winter haze period, DMP, DBP, and DEHP were the PAE monomers with significantly increased concentrations outdoors, whereas DEHP concentration was increased the most significantly indoors.

As shown in Fig. 4, outdoor PAEs in the spring haze were mainly DMP and DEHP, whereas in the winter haze, the main PAEs were DMP, DBP, and DEHP. During the winter haze, the concentrations of pollutants in $\mathrm{PM}_{2.5}$ were increased due to adverse weather factors, which caused the outdoor PAE concentration to gradually increase. No obvious change in indoor PAE concentration occurred during the winter haze, mainly because people would close their windows on hazy days, which caused poor air circulation in the indoor environment. This indicates that indoor PAE concentration was mainly affected by indoor PAE sources.

\section{Molecular Monomer Distributions and Possible Sources of Phthalates in PM 2.5}

Concentrations of indoor and outdoor PAE monomers (DMP, DEP, DEBP, BBP, DEHP, and DnOP) are shown in Table 3 and Fig. 5, and significant characteristics of the main monomers are given. DBP and DEHP were the predominant monomers, followed by DMP, with other PAE monomers being relatively minor. In spring, DBP accounted for $72 \%$ of indoor and $39 \%$ of outdoor PAEs, whereas DEHP accounted for $27 \%$ of indoor and $48 \%$ of outdoor PAEs. Similarly, DBP accounted for $62 \%$ of indoor and $45 \%$ of outdoor PAEs in winter, whereas DEHP accounted for $32 \%$ of indoor and $30 \%$ of outdoor PAEs. The next highest concentrations were those of DMP and DEP, and the concentration of DnOP was minimal. This means that DBP and DEHP are the two main components of PAE pollution, which is likely because these are the two most widely used plasticizers in China.

Differences in the main PAE monomer pollutants were primarily due to the local major industries, consumer goods, and consumption levels. Outdoor DBP and DEHP were mainly from the plastic products industry and various other sources of fuel emissions. According to a statistical survey
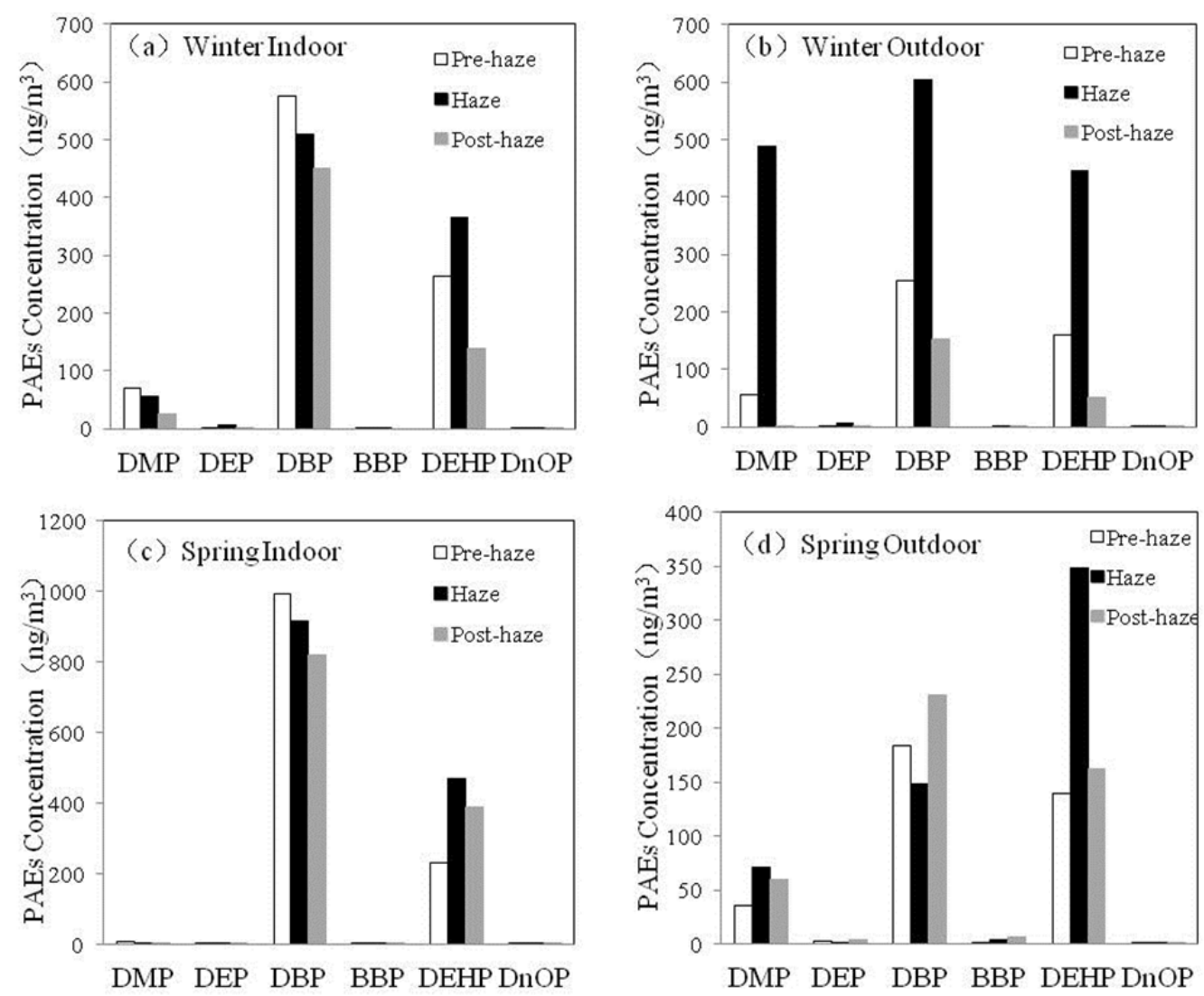

Fig. 4. Mass concentration of phthalate monomers in indoor and outdoor $\mathrm{PM}_{2.5}$ during haze periods. 
Table 3. Concentration of PAEs in indoor and outdoor $\mathrm{PM}_{2.5}$ in different seasons (mean \pm standard deviation, unit: $\mathrm{ng}^{-3}$ ).

\begin{tabular}{llllll}
\hline \multirow{2}{*}{ PAEs } & \multicolumn{2}{c}{ Spring } & & \multicolumn{2}{c}{ Winter } \\
\cline { 2 - 3 } \cline { 5 - 6 } & Indoor & Outdoor & & Indoor & Outdoor \\
\hline DMP & $5.20 \pm 6.72$ & $52.33 \pm 35.83$ & & $44.74 \pm 29.65$ & $203.68 \pm 259.57$ \\
DEP & $1.64 \pm 2.07$ & $2.58 \pm 3.87$ & & $2.70 \pm 3.73$ & $3.17 \pm 6.13$ \\
DBP & $936.18 \pm 331.13$ & $179.66 \pm 60.98$ & & $529.78 \pm 112.10$ & $363.28 \pm 208.68$ \\
BBP & $0.43 \pm 0.53$ & $3.09 \pm 2.47$ & & $1.00 \pm 1.10$ & $0.11 \pm 0.23$ \\
DEHP & $343.99 \pm 175.50$ & $217.44 \pm 133.54$ & & $277.62 \pm 131.654$ & $244.37 \pm 183.84$ \\
DnOP & $0.60 \pm 0.71$ & $0.73 \pm 0.71$ & & $0.75 \pm 1.14$ & $0.61 \pm 0.99$ \\
Concentration & $1288.03 \pm 379.02$ & $455.82 \pm 97.65$ & & $856.59 \pm 217.93$ & $815.22 \pm 156.48$ \\
\hline
\end{tabular}
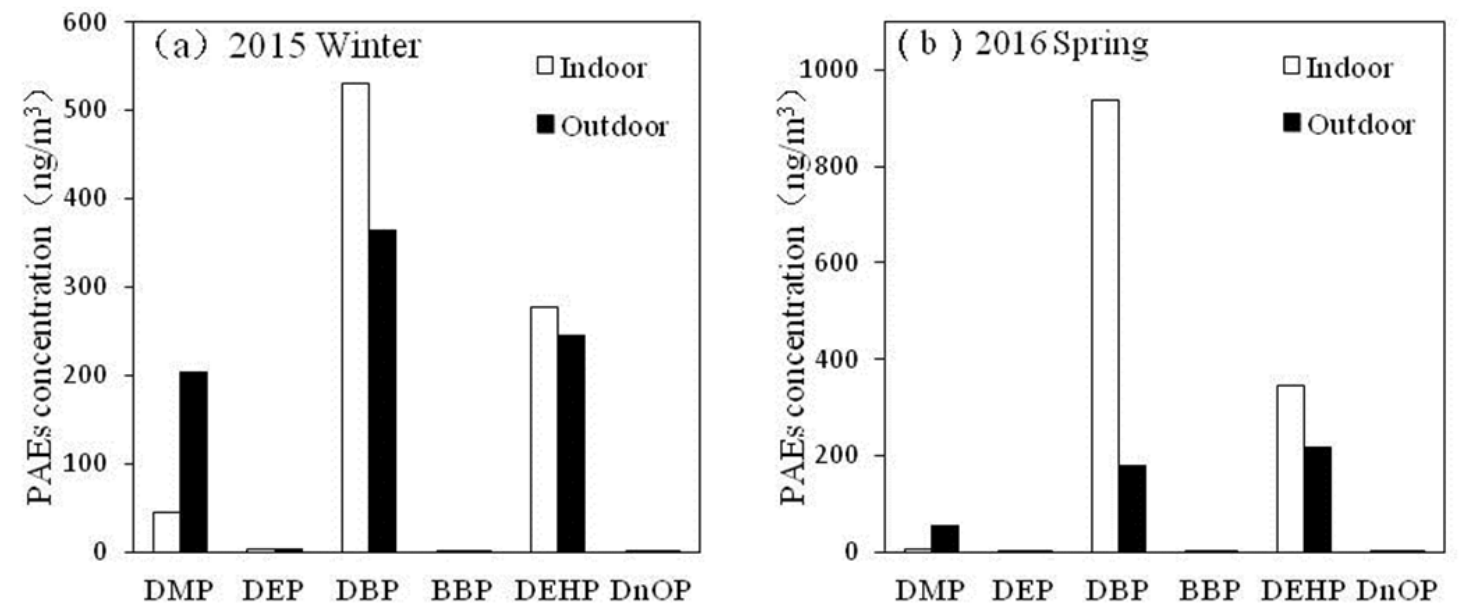

Fig. 5. Mass concentration of phthalate monomers in indoor and outdoor $\mathrm{PM}_{2.5}$ during winter and spring.

of plasticizer-related industries in China, current plasticizer production and consumption are mainly based on DEHP and DBP, with these PAEs accounting for more than $80 \%$ of the total. The lower occurrence of DEP, BBP, and DnOP in $\mathrm{PM}_{2.5}$ samples may be related to their low production and minimal use as plasticizers. Therefore, we further analyzed the major PAE pollution monomers (DMP, DBP, and DEHP).

Table 4 shows correlations between different PAE monomers indoors and outdoors. In spring, no obvious correlations $(p>0.05)$ were found between different PAE monomers either indoors or outdoors, whereas in winter, although there were no significant correlations $(p>0.05)$ between different PAE monomers indoors, the correlation coefficient of paired outdoor concentrations of DMP and DBP was $0.742(p<0.05)$, and it was $0.954(p<0.05)$ for paired concentrations of DBP and DEHP. After excluding paired concentrations with the maximum or minimum values of DMP and DEHP in outdoor conditions in winter, paired concentrations of DMP and DEHP were also significantly correlated $(p<0.05)$, with the correlation coefficient changing from 0.662 to 0.812 . The significant correlations between DMP, DBP, and DEHP suggest a strong possibility that these PAEs are released from the same sources in winter outdoor conditions, whereas indoor sources of PAEs in Beijing are more diverse and complicated.

Numerous plastic products were present in the room investigated in this study, and the desk surface had a plastic paint veneer. The interior decor also revealed various plastic hot-melt adhesives, coatings, and ink additives, which are major sources of indoor PAEs.

\section{Exposure Risk Assessment for Phthalates in PM 2.5}

PAEs are an endocrine disrupter with an estrogenic function. U.S. studies have shown that trace amounts of DEHP have a major effect on human health and strong carcinogenicity at low concentrations. However, no indoor air phthalate quality standard has yet been defined, either in China or abroad, and the exposure hazards of indoor air phthalates have not been clearly determined. The Integrated Risk Information System in the United States evaluates the inhalationexposure carcinogenicity of phthalates in the air. China's indoor air phthalate concentration is relatively high; because such pollution represents a potential hazard for the human body, the health risk should be taken seriously.

As a class of anti-androgen endocrine disruptors and B2 carcinogens, phthalates mainly pose anti-androgen effect and carcinogenic risks, with a greater risk of carcinogenesis from exposure to phthalates in indoor air. In this study, carcinogenic risk was estimated for exposure to phthalates in indoor air in Beijing. The carcinogenic risk value $R$ can be calculated using the following equation (U.S. EPA, 2000):

$R=q \times E$

where $R$ is the phthalates carcinogenic risk value, $q$ is the 
Table 4. Correlation coefficient matrix of different fine PAEs, comparing indoors with outdoors.

\begin{tabular}{|c|c|c|c|c|c|}
\hline & & & DMP & DBP & DEHP \\
\hline \multirow[t]{6}{*}{ Spring } & Indoor & DMP & 1.000 & & \\
\hline & & DBP & 0.340 & 1.000 & \\
\hline & & DEHP & -0.529 & 0.293 & 1.000 \\
\hline & Outdoor & DMP & 1.000 & & \\
\hline & & DBP & 0.192 & 1.000 & \\
\hline & & DEHP & 0.532 & -0.162 & 1.000 \\
\hline \multirow[t]{6}{*}{ Winter } & Indoor & DMP & 1.000 & & \\
\hline & & DBP & 0.568 & 1.000 & \\
\hline & & DEHP & 0.495 & 0.680 & 1.000 \\
\hline & Outdoor & DMP & 1.000 & & \\
\hline & & DBP & 0.742 & 1.000 & \\
\hline & & DEHP & 0.662 & 0.954 & 1.000 \\
\hline
\end{tabular}

carcinogenic slope factor and equal to $0.014\left(\mathrm{mg} \mathrm{kg}^{-1} \mathrm{~d}^{-1}\right)^{-1}$ for DEHP (U.S. EPA, 1997a), and $E$ is the PAE exposure in $\mathrm{mg} \mathrm{kg}^{-1} \mathrm{~d}^{-1}$ ).

PAEs enter the human body mainly through inhalation and skin contact; inhalation exposure was calculated using the following equation (U.S. EPA, 1997b):

$I E=\frac{C_{i} \times I R \times C F \times E D}{B W}$

where $I E$ is inhalation exposure (unit: $\mu \mathrm{g} \mathrm{kg}^{-1} \mathrm{~d}^{-1}$ ), $C_{i}$ is the total concentration of PAEs $\left(\mu \mathrm{g} \mathrm{m}^{-3}\right), I R$ is the respiration rate $\left(\mathrm{m}^{3} \mathrm{~d}^{-1}\right), C F$ is the unit conversion factor (equal to $1 / 24), E D$ is exposure time $\left(\mathrm{h} \mathrm{d}^{-1}\right)$, and $B W$ is the mass of the exposed body $(\mathrm{kg})$.

Skin exposure was calculated using the following equation (U.S. EPA, 1992):

$D E=\frac{C_{i} \times S A \times f_{S A} \times P \times E D \times F}{B W}$

where $D E$ is skin contact exposure $\left(\mu \mathrm{g} \mathrm{kg}^{-1} \mathrm{~d}^{-1}\right), C_{i}$ is the gas pollutant concentration $\left(\mu \mathrm{g} \mathrm{m}^{-3}\right), S A$ is the skin surface area $\left(\mathrm{m}^{2}\right), f_{S A}$ is the ratio of skin to air contact (a value of 0.25 is assumed for a person wearing short pants), $P$ is the total permeability coefficient of the skin $\left(P=580 \mathrm{~cm} \mathrm{~h}^{-1}\right.$ for DEHP; Xu et al., 2009), and $F$ is the unit conversion factor (the value is 0.01); the remaining parameters are the same as in Eq. (2).

The gas PAEs concentration was estimate using the following equation:

$C_{g}=\frac{C_{p}}{K}$

where $C_{g}$ is the gas pollutant concentration $\left(\mu \mathrm{g} \mathrm{m}^{-3}\right), C_{p}$ is the fine pollutant concentration $\left(\mu \mathrm{g} \mathrm{m}^{-3}\right), K$ is the ratio factor between gas and fine phase of DEHP (Pei, 2013).

The indoor DEHP inhalation and skin exposure for different age groups, calculated using Eqs. (1)-(4), are shown in Tables 5 and 6. Parameters such as age, respiration rate, body weight, exposure time, and skin surface area were referenced from the U.S. EPA's recommended values.

The results showed that DEHP inhalation exposure was the highest for children aged $1-2$ years at $0.29 \mu \mathrm{g} \mathrm{kg}^{-1} \mathrm{~d}^{-1}$ in winter and $0.36 \mu \mathrm{g} \mathrm{kg}^{-1} \mathrm{~d}^{-1}$ in spring, followed by children aged 2-3, for whom inhalation exposure was $0.25 \mu \mathrm{g} \mathrm{kg}^{-1} \mathrm{~d}^{-1}$ in winter and $0.31 \mu \mathrm{g} \mathrm{kg}^{-1} \mathrm{~d}^{-1}$ in spring. From the 2-3 to 16-21 year age groups, DEHP inhalation exposure gradually decreased with age. Likewise, children aged 1-2 had the highest skin exposure, which was $0.31 \mu \mathrm{g} \mathrm{kg}^{-1} \mathrm{~d}^{-1}$ in winter and $0.38 \mu \mathrm{g} \mathrm{kg}^{-1} \mathrm{~d}^{-1}$ in spring, slightly higher than the inhalation exposure; DEHP skin exposure was lower for children aged $2-3$. The calculation results showed that the exposure value was lower than the U.S. EPA limit of $20 \mu \mathrm{g} \mathrm{kg}^{-1} \mathrm{~d}^{-1}$, but this does not mean that PAEs pose no health hazards. Multiple PAEs may exert synergistic effects on health. Additionally, this study did not consider food, drinking water, and other media through which PAEs could enter the body; nor did it consider the intake of PAEs in children from interaction with toys. Methods of determining exposure to PAEs through these pathways should be further explored. Our results showed that total exposure to DEHP in children was significantly higher than in adults, with the most serious health hazards for children aged 1-2.

A carcinogenic risk value of under $1 \times 10^{-6}$ indicates that the risk is small, whereas a risk value of more than $1 \times$ $10^{-4}$ indicates a high risk, requiring careful attention and appropriate measures. In this study, we found that DEHP exposure in winter and spring in Beijing had the strongest effect on children aged 1-2, and their carcinogenic risk in winter and spring was $8.47 \times 10^{-6}$ and $10.50 \times 10^{-6}$, respectively (Table 7). Thus, there was some risk of cancer from DEHP exposure in 1-2-year-old children. With increasing age, the risk of cancer was discovered to gradually decrease. People 16-21 years old or older than 21 had a small risk of exposure- $3.30 \times 10^{-6}$ in winter and $4.09 \times 10^{-6}$ in spring-but this is still higher than the threshold carcinogenic risk value. Indoor phthalate pollution thus poses a serious carcinogenic risk because it exerts anti-androgen effects on human health; attention should be paid and effective measures proposed to control PAE contamination. 
Table 5. Inhalation exposure to DEHP in different seasons.

\begin{tabular}{llllll}
\hline Age (year) & $\begin{array}{l}\text { Respiration rate } \\
\left(\mathrm{m}^{3} \mathrm{~d}^{-1}\right)\end{array}$ & $\begin{array}{l}\text { Body weight } \\
(\mathrm{kg})\end{array}$ & $\begin{array}{l}\text { Exposure time } \\
(\mathrm{h} \mathrm{d})\end{array}$ & \multicolumn{2}{c}{$\sum \operatorname{IE~}\left(\mu \mathrm{gg} \mathrm{kg}^{-1} \mathrm{~d}^{-1}\right)$} \\
\hline $0-1$ & 5.4 & 9.1 & 19.6 & 0.31 & Winter \\
$1-2$ & 8 & 11.3 & 19.5 & 0.36 & 0.25 \\
$2-3$ & 8.9 & 13.3 & 17.8 & 0.31 & 0.29 \\
$3-6$ & 10.1 & 17.5 & 17.2 & 0.26 & 0.21 \\
$6-11$ & 12 & 28.7 & 18 & 0.20 & 0.16 \\
$11-16$ & 15.2 & 50.2 & 15.6 & 0.12 & 0.10 \\
$16-21$ & 16.3 & 64.3 & 15.6 & 0.10 & 0.08 \\
\hline
\end{tabular}

Table 6. Skin exposure to DEHP in different seasons.

\begin{tabular}{llllll}
\hline Age (year) & $\begin{array}{l}\text { Respiration rate } \\
\left(\mathrm{m}^{3} \mathrm{~d}^{-1}\right)\end{array}$ & $\begin{array}{l}\text { Body weight } \\
(\mathrm{kg})\end{array}$ & $\begin{array}{l}\text { Exposure time } \\
\left(\mathrm{h} \mathrm{d}^{-1}\right)\end{array}$ & \multicolumn{2}{c}{$\sum \mathrm{DE}\left(\mu \mathrm{kg} \mathrm{kg}^{-1} \mathrm{~d}^{-1}\right)$} \\
\hline $0-1$ & 0.36 & 9.1 & 19.6 & Spring & Winter \\
$1-2$ & 0.53 & 11.3 & 19.5 & 0.33 & 0.26 \\
$2-3$ & 0.61 & 13.3 & 17.8 & 0.34 & 0.31 \\
$3-6$ & 0.76 & 17.5 & 17.2 & 0.31 & 0.28 \\
$6-11$ & 1.08 & 28.7 & 18 & 0.29 & 0.25 \\
$11-16$ & 1.59 & 50.2 & 15.6 & 0.21 & 0.23 \\
$16-21$ & 1.84 & 64.3 & 15.6 & 0.19 & 0.17 \\
\hline
\end{tabular}

Table 7. Carcinogenic risk of DEHP in indoor air for different age groups.

\begin{tabular}{lllllllll}
\hline \multirow{2}{*}{ DEHP } & \multirow{2}{*}{ Season } & $\begin{array}{l}0-1 \\
\text { years old }\end{array}$ & $\begin{array}{l}1-2 \\
\text { years old }\end{array}$ & $\begin{array}{l}2-3 \\
\text { years old }\end{array}$ & $\begin{array}{l}3-6 \\
\text { years old }\end{array}$ & $\begin{array}{l}6-11 \\
\text { years old }\end{array}$ & $\begin{array}{l}11-16 \\
\text { years old }\end{array}$ & $\begin{array}{l}16-21 \\
\text { years old }\end{array}$ \\
\hline carcinogenic risk R & Spring & 8.87 & 10.50 & 9.22 & 8.07 & 6.78 & 4.66 & 4.09 \\
$\left(\times 10^{-6}\right)$ & Winter & 7.16 & 8.47 & 7.44 & 6.52 & 5.47 & 3.76 & 3.30 \\
\hline
\end{tabular}

\section{CONCLUSION}

(1) The concentration of phthlates in $\mathrm{PM}_{2.5}$ in Beijing is relatively high and exhibits some seasonal variation. During the time of our study, it was significantly higher both indoors and outdoors during periods of haze than before the haze, reaching a maximum concentration (indoors) of $1995.56 \mathrm{ng} \mathrm{m}^{-3}$. Furthermore, the concentration indoors was generally higher than outdoors, indicating that the main sources of phthalates in indoor environments were indoor. The primary PAEs found outdoors during spring haze were DMP and DEHP, whereas those during winter haze were DMP, DBP, and DEHP. During winter haze, the amount of phthalates in the $\mathrm{PM}_{2.5}$ significantly increased, but the indoor concentration did not significantly change, supporting the conclusion of indoor sources.

(2) By calculating the DEHP exposure of children and adults via inhalation and skin contact, we discovered that 1-2-year-old children were the highest risk group in Beijing during winter and spring, with a level of exposure exceeding that associated with the minimum risk. From the age of 2 or 3 , the risk of carcinogenesis decreased with age; according to our calculations, the level of exposure was lower than the U.S. EPA limit of $20 \mu \mathrm{g} \mathrm{kg}^{-1} \mathrm{~d}^{-1}$. Nevertheless, the carcinogenic risk and anti-androgen effects of PAEs represent a serious risk to human health, and the synergistic effects of multiple PAEs, due to the variety of indoor contact media, also impact the human body. Thus, effective measures are required to control PAE pollution.

\section{ACKNOWLEDGEMENTS}

This work was partly supported by the Beijing Municipal Natural Science Foundation (L150001) and the Beijing Academy of Science and Technology's Green Shoots Plan (201706).

\section{REFERENCES}

Al-Saleh, I., Elkhatib, R., Al-Rajoudi, T. and Al-Qudaihi, G. (2017). Assessing the concentration of phthalate esters (PAEs) and bisphenol-a (BPA) and the genotoxic potential of treated wastewater (final effluent) in Saudi Arabia. Sci. Total Environ. 578: 440-451.

Axelsson, J., Rylander, L., Rignell-Hydbom, A., Lindh, C.H., Jonsson, B.A. and Giwercman, A. (2015). Prenatal phthalate exposure and reproductive function in young men. Environ. Res. 138: 264-270.

Bamai, Y.A., Araki, A., Kawai, T., Tsuboi, T., Saito, I., Yoshioka, E., Cong, S. and Kishi, R. (2016). Exposure to phthalates in house dust and associated allergies in children aged 6-12 years. Environ. Int. 96: 16-23.

Castro, D., Slezakova, K., Delerue-Matos, C., Alvim-Ferraz, M.D., Morais, S. and Pereira, M.D. (2011). Polycyclic aromatic hydrocarbons in gas and particulate phases of 
indoor environments influenced by tobacco smoke: Levels, phase distributions, and health risks. Atmos. Environ. 45: 1799-1808.

EC (1997). Concerning the third list of priority substances as foreseen under Council Regulation (EEC) No 793/93. Off. J. Eur. Communities 25: 13-14.

Fromme, H., Lahrz, T., Piloty, M., Gebhart, H., Oddoy, A.H. and Ruden, H. (2004). Occurrence of phthalates and musk fragrances in indoor air and dust from apartments and kindergartens in Berlin (Germans). Indoor Air 14: 188-195.

Fu, P.Q., Kawamura, K., Pavuluri C.M., Swaminathan, T. and Chen, J. (2010). Molecular characterization of urban organic aerosol in tropical India: Contributions of primary emissions and secondary photooxidation. Atmos. Chem. Phys. 10: 2663-2689.

Gu, Z., Feng, J.L., Han, W., Wu, M., Fu, J.M. and Sheng, G.Y. (2010). Characteristics of organic matter in $\mathrm{PM}_{2.5}$ from an e-waste dismantling area in Taizhou, China. Chemosphere 80: 800-806.

Guo, Y. and Kannan, K. (2013). A survey of phthalates and parabens in personal care products from the United States and its implications for human exposure. Environ. Sci. Technol. 47: 14442-14449.

Hauser, R., Meeker, J.D., Duty, S., Silva, M.J. and Calafat, A.M. (2006). Altered semen quality in relation to urinary concentrations of phthalate monoester and oxidative metabolites. Epidemiology 17: 682-691.

IARC (1982). Di (2-ethylhexyl) phthalate. International agency for research on cancer (IARC) monographs on the evaluation of carcinogenic risks to humans $29, \mathrm{pp}$. 269-294.

Kong, S.F., Ji, Y.Q., Liu, L.L., Chen, L., Zhao, X.Y., Wang, J.J., Bai, Z.P. and Sun, Z.R. (2013). Spatial and temporal variation of phthalic acid esters (PAEs) in atmospheric $\mathrm{PM}_{10}$ and $\mathrm{PM}_{2.5}$ and the influence of ambient temperature in Tianjin, China. Atmos. Environ. 74: 199-208.

Li, J.J. and Wang, G.H. (2015). Airborne particulate endocrine disrupting compounds in China: Compositions, size distributions and seasonal variations of phthalate esters and bisphenol. Atmos. Res. 154: 138-145.

Pei, X.Q. (2013). Pollution characteristics and health risk of phthalates in indoor air. Zhejiang University, China.

Pei, X.Q., Song, M., Guo, M., Mo, F.F. and Shen, X.Y. (2013). Concentration and risk assessment of phthalates present in indoor air from newly decorated apartments. Atmos. Environ. 68: 17-23.

Peijnenburg, W.J.G.M. and Struijs, J. (2006). Occurrence of phthalate esters in the environment of the Netherlands. Ecotoxicol. Environ. Saf. 63: 204-205.

Rudel, R.A., Camann, D.E., Spengler, J.D., Korn, L.R. and Brody, J.G. (2003). Phthalates, alkylphenols, pesticides, polybrominated diphenyl ethers, and other endocrinedisrupting compounds in indoor air and dust. Environ. Sci. Technol. 37: 4543-4553.

Shen, T. (2009). Analysis of phthalates in indoor air and dust. Beijing University of Technology, China.

Škrbic, B.D., Ji, Y.Q., Durisic-Mladenovic, N. and Zhao, J. (2016). Occurence of the phthalate esters in soil and street dust samples from the Novi Sad city area, Serbia, and the influence on the children's and adults' exposure. J. Hazard. Mater. 312: 272-279.

Song, M., Chi, C., Guo, M., Wang, X., Cheng, L. and Shen, X. (2015). Pollution levels and characteristics of phthalate esters in indoor air of offices. J. Environ. Sci. 28: 157-162.

Sun, Y.L., Jiang, Q., Wang, Z., Fu, P.Q., Li, J., Yang, T. and Yin, Y. (2014). Investigation of the sources and evolution processes of severe haze pollution in Beijing in January 2013. J. Geophys. Res. Atmos. 119: 4380-4398.

Sun, Y.L., Wang, Z.F., Du, W., Zhang, Q., Wang, Q.Q., Fu, P.Q., Pan, X.L., Li, J., Jayne, J. and Worsnop, D.R. (2015). Longterm real-time measurements of aerosol particle composition in Beijing, China: Seasonal variations, meteorological effects, and source analysis. Atmos. Chem. Phys. 15: 10149-10165.

Sun, Y.L., Chen, C., Zhang, Y., Xu, W.Q., Zhou, L.B., Cheng, X.L., Zheng, H.T., Ji, D.S., Li, J., Tang, X., Fu, P.Q. and Wang, Z.F. (2016). Rapid formation and evolution of an extreme haze episode in Northern China during winter 2015. Sci. Rep. 6: 27151.

Teil, M.J., Blanchard, M. and Chevreuil, M. (2006). Atmospheric fate ofphthalate esters in an urban area (Paris-France). Sci. Total Environ. 354: 212-223.

U.S. EPA (1992). Dermal Exposure Assessment: Principles and Applications. EPA/600/8-91/O11B.

U.S. EPA (1997a). Integrated Risk Information System. Di(2-ethylhexyl)phthalate(DEHP) (CASRN117-81-7). http://www.epa.gov/iris/subst/0014.htm.

U.S. EPA (1997b). Exposure factors handbook. National Center for Environmental Assessment. EPA/600/P95/002F(a-c). Washington D.C.

U.S. EPA (2000). Exposure and human health reassessment of 2,3,7,8-Tetrachlorodibenzo- $p$-dioxin (TCDD) and related compounds. Part 1: Estimating exposure to dioxin-like compounds. National Center for Environmental Assessment, Office of Research and Development. EPA/600/P-00/001 B(b-d).

U.S. EPA (2012). Phthalates action plan. Washington, DC: U.S. EPA. http://www.epa.gov/oppt/existingchem icals/pubs/actionplans/phthalates_actionplan_revised_20 12-03-14.pdf.

Wang, G.H., Kawamura, K. and Lee, M. (2009). Comparison of organic compositions in dust storm and normal aerosol samples collected at Gosan, Jeju Island, during spring 2005. Atmos. Environ. 43: 219-227.

Wang, G.H., Kawamura, K., Lee, S., Ho, K.F. and Cao, J.J. (2006). Molecular, seasonal and spatial distributions of organic aerosols from fourteen Chinese cities. Environ. Sci. Technol. 40: 4619-4625.

Wang, J.Z., Dong, Z.B., Li, X.P., Gao, M.L., Ho, S.S.H., Wang, G.H., Xiao, S. and Cao, J.J. (2018). Intra-urban levels, spatial variability, possible sources and health risks of $\mathrm{PM}_{2.5}$ bound phthalate esters in Xi'an. Aerosol Air Qual. Res. 18: 485-496.

Wang, P., Wang, S.L. and Fan, C.Q. (2008). Atmospheric distribution of particulate- and gas-phase phthalic esters (PAEs) in a Metropolitan City, Nanjing, East China. 
Chemosphere 72: 1567-1572.

Wang, X.K., Tao, W., Xu, Y., Feng, J.T. and Wang, F.H. (2014). Indoor phthalate concentration and exposure in residential and office buildings in Xi'an, China. Atmos. Environ. 87: 146-152.

Wensing, M., Uhde, E. and Salthammer, T. (2005). Plastics additives in the indoor environment - flame retardants and plasticizers. Sci. Total Environ. 339: 19-40.

Weschler, C., Salthammer, T. and Fromme, H. (2008). Partitioning of phthalates among the gas phase, airborne particles and settled dust in indoor environments. Atmos. Environ. 42: 1449-1460.

Xu, Y., Hubal, E.A.C. and Clausen, P.A. (2009). Predicting residential exposure to phthalate plasticizer emitted from vinyl flooring: A mechanistic analysis. Environ. Sci. Technol. 43: 2374-2380.
Zhang, L.B., Wang, F.M., Ji, Y.Q., Jiao, J., Zou, D.K., Liu, L.L., Shan, C.Y., Bai, Z.P. and Sun, Z.R. (2014). Phthalate esters (PAEs) in indoor $\mathrm{PM}_{10} / \mathrm{PM}_{2.5}$ and human exposure to PAEs via inhalation of indoor air in Tianjin, China. Atmos. Environ. 85: 139-146.

Zhao, L., Chen, C., Wang, P., Chen, Z.G., Cao, S.J., Wang, Q.Q., Xie, G.Y., Wan, Y.L., Wang, Y.F. and Lu, B. (2015). Influence of atmospheric fine particulate matter $\left(\mathrm{PM}_{2.5}\right)$ pollution on indoor environment during winter in Beijing. Build. Environ. 87: 283-291.

Received for review, April 28, 2018 Revised, September 18, 2018 Accepted, September 20, 2018 